\title{
Hierarchizing caries risk factors among first- year university students in Nice (France): a cross-sectional study
}

\author{
Romain Ceinos ${ }^{1,2}$, Marie-France Bertrand ${ }^{1,3,45^{*}}$ (D) Céline Cucchi ${ }^{1}$ and Laurence Lupi ${ }^{1,3,4}$
}

\begin{abstract}
Background: The purpose of this study was to rank the risk factors for dental caries among first-year university students in Nice (France).

Methods: All first-year students are required to undergo a compulsory preventive medical examination. Among these students, volunteers were offered a dental visit. Information was collected through an interview followed by an oral examination. We assessed the volunteers' oral hygiene habits (daily toothbrushing frequency, type of toothbrush used, frequency of toothbrush replacement, place of toothpaste purchase, and flossing), daily health-related behaviors (number of main daily meals, daily sugary intakes, smoking, alcohol consumption, consumption of cannabis or other drugs), oral-health-related behaviors (self-reported oral health, dental visits during the past year, reason for the last dental consultation, and failure to seek dental care due to financial reasons), and oral health issues (dental crowding, oral hygiene, presence of caries, presence of pit and fissure sealant remnants). The dependent variable was the presence of at least one untreated carious lesion. The data were subjected to univariate analyses to select explanatory variables, and subsequently, a logistic regression was performed.
\end{abstract}

Results: Six hundred twenty-nine students aged 18.8 1.6 years were enrolled in this study. The sex ratio was 0.72 , with a strong predominance of the female gender. Only $59.3 \%$ of the students had never experienced dental caries, while $22.4 \%$ had already undergone restorative procedures and did not have any carious lesion at the time of the examination, and $11.6 \%$ presented with carious lesions and had never been treated by a dentist. Lastly, $6.7 \%$ had carious lesions despite evidence of prior restorative procedures. The multivariate analysis revealed the following pejorative risk factors: failure to seek dental care due to financial reasons (OR:3.06, 95\% Cl: 1.40-6.70), poor oral hygiene revealed during the oral examination (OR:2.59, 95\% Cl: 1.60-4.20), and poor self-reported oral health (OR:2.43, 95\% Cl: 1.24-4.77). Conversely, the analysis revealed the following protective factors: preventive visits to the dentist (OR:0.63, 95\% Cl: $0.41-0.99)$, the use of an electric toothbrush (OR:0.36, 95\% Cl: 0.17-0.77), and sealant remnants (OR:0.22, 95\% Cl: 0.05-0.97).

Conclusions: The highest-ranking caries risk factor for the study population was the financial barrier.

Keywords: Health-related behavior, Dental caries, First-year university students, Multivariate analysis

\footnotetext{
* Correspondence: Marie-France.BERTRAND@unice.fr

'Université Côte d'Azur, UFR Odontologie, 24 avenue des diables bleus,

06357 Nice cedex 4, France

${ }^{3}$ Université Côte d'Azur, MICORALIS, 24 avenue des diables bleus, 06357 Nice

cedex 4, France

Full list of author information is available at the end of the article
} 


\section{Background}

In 2006, a French national report revealed that university students neglected their health [1]. These young adults think they are healthy and feel invulnerable. In general, they had poor dietary and oral hygiene habits and often failed to seek dental care. The report also noted risk behaviors, particularly smoking, excessive alcohol consumption, and the daily use of certain drugs considered to be less dangerous than tobacco, particularly cannabis. Over the last 10 years, particular emphasis has been placed upon promoting a balanced diet and the prevention of risk behaviors in French universities.

In a review published in The Lancet by Selwitz et al. in 2007, caries risk assessment included physical, biological, environmental, behavioral, and lifestyle-related factors [2]. The individual caries risk can vary with time since many risk factors are changeable. Caries is related to one's lifestyle, and behavioral factors under a person's control are clearly implicated [3-6]. These factors include poor oral hygiene [7-9] and poor dietary habits [10-13]. Other factors related to caries risk include socio-economic status $[3,5,6]$, the use of dental sealants $[14,15]$, and dental crowding, which promotes plaque retention and increases the difficulty of maintaining good oral hygiene [16]. Besides, the relative caries preventive effects of fluoride toothpastes of different concentrations increase with higher fluoride concentration [17]. Though, in France, toothpastes sold in pharmacies need a special authorization (AMM) because the amount of fluorides is high (1500 ppm and more), and they are therefore considered as medicines. Because they are less fluoridated (1450 ppm and less), toothpastes in supermarkets are considered as hygiene products.

Numerous studies performed among undergraduate students have concerned dental students [18] but have less often studied the general university student population. However, dental students constitute a selected minority that is clearly demarcated from students of other disciplines regarding a higher awareness of selfreliant oral hygiene [18]. The DMFT score of undergraduate students has been the object of studies in various universities worldwide. Studies in Europe, North America, Asia and the Middle East show that the DMFT score of undergraduate students range from $4.1 \pm 3.1$ at Sana'a University in Yemen [19] to $3.9 \pm 3.9$ at San Luis Potosí University in Mexico [20], 2.9 \pm 3.3 at Helsinki University in Finland [21], 2.0 \pm 2.9 at Okayama University in Japan [22], and $1.2 \pm 2.0$ at Nice Sophia Antipolis University in France [23].

Low sugar consumption and good oral hygiene are critical for the prevention of caries and the maintenance of good oral health [24]. In Lebanon, 65\% of undergraduate students reported brushing their teeth at least twice per day [25], while that percentage was $68 \%$ in
Turkey [26], 74\% in the USA [27], 87\% in Japan [28], and $92 \%$ in Italy [29] and France [23]. Of subjects in Turkey, 91\% reported never flossing versus $87 \%$ in Japan, $80 \%$ in France, $72 \%$ in Lebanon, 35\% in Italy and $20 \%$ in the USA. Of the students in France and Italy, 62\% and $60 \%$, respectively, reported visiting a dentist during the previous year, while these percentages were only $31 \%$ in Lebanon and $30 \%$ in Turkey. High sugar consumption has long been linked to dental caries [30]. A quarter of USA Midwestern university students reported eating sugary foods (including foods and drinks, such as candies, soft drinks, juices, doughnuts, jellies, etc.) more than once daily. Among the $89 \%$ of students who reported drinking pop, $69 \%$ selected regular pop as their favorite as opposed to diet pop [27].

Smoking habits may also be associated with a higher risk of dental caries [31]. Self-reported use of tobacco among adolescents was significantly associated with an increased incidence of dental caries over a 3-year period [32]. This association was also apparent with alcohol [33-35] and drug abuse [36-38].

No data are available in France concerning the specific caries risk factors among university students. However, in France, university students often leave their family for the first time to study at a university that occasionally is far from home [39]. This assertion of autonomy may be particularly risky for their oral health. A national survey was conducted in Finland, and based on the university health department registries, an electronic questionnaire was sent to first-year students on their general, emotional, and oral health [40]. This survey revealed an increased risk of deterioration of oral health and thus a need for treatment in relation to poor habits regarding oral health and diet.

In France, all university students in their first 3 years of study are required to attend a preventive medical consultation [41]. In the Côte d'Azur University, this consultation takes place during the first year of study. A preventive dental consultation conducted by final-year dental students has also been implemented for more than 10 years. The purpose of this study was to rank the risk factors for dental caries among first-year university students.

\section{Methods}

\section{Study population}

A cross-sectional epidemiological study was conducted at the Côte d'Azur University. The study was approved by the University institutional review board (Commission de la Formation et de la Vie Universitaire). A previous study conducted on 4929 students of Nice-Sophia Antipolis University from 2009 to 2011 revealed that $43 \%$ of the students had at least one carious lesion [23]. The sample size 
Table 1 Background factors, daily health-related behaviors and oral-health behaviors among the first-year students of Nice Côte d'Azur University

\begin{tabular}{|c|c|c|c|c|c|}
\hline \multicolumn{3}{|l|}{ u Azui Universily } & \multicolumn{3}{|l|}{ u Azur Umiversily (comimued) } \\
\hline & $\mathrm{N}$ & $\%$ & & $\mathrm{~N}$ & $\%$ \\
\hline Gender & & & No & 496 & 78.9 \\
\hline Male & 263 & 41.8 & Drink consumed when thirsty & & \\
\hline Female & 366 & 58.2 & Water & 483 & 76.8 \\
\hline Area of study & & & Other drink & 146 & 23.2 \\
\hline Health, Sport & 275 & 43.7 & Daily toothbrushing frequency & & \\
\hline Science, Technology & 91 & 14.5 & One time & 78 & 12.4 \\
\hline Law, Economics, Management, Business & 163 & 25.9 & Two times & 446 & 70.9 \\
\hline Letters, Arts and Humanities & 100 & 15.9 & Three times & 101 & 16.1 \\
\hline Social security coverage & & & Not every day & 4 & 0.6 \\
\hline French social security system & 36 & 5.7 & Type of toothbrush used & & \\
\hline French social security system + & 588 & 93.5 & Manual & 530 & 84.3 \\
\hline universal health-care coverage & & & Electric & 99 & 15.7 \\
\hline Other systems & 5 & 0.8 & Toothbrush replacement at least every three months & & \\
\hline Father's profession & & & Yes & 460 & 73.1 \\
\hline Managing profession & 313 & 49.8 & No & 169 & 26.9 \\
\hline Employees & 214 & 34.0 & Place of purchase of toothpaste & & \\
\hline Without employment & 70 & 11.1 & Pharmacy & 58 & 9.2 \\
\hline Not documented or deceased & 32 & 5.1 & Supermarket & 490 & 77.9 \\
\hline Mother's profession & & & Not known & 81 & 12.9 \\
\hline Managing profession & 202 & 32.1 & Flossing & & \\
\hline Employees & 301 & 47.9 & Yes & 76 & 12.1 \\
\hline Without employment & 116 & 18.4 & No & 553 & 87.9 \\
\hline Not documented or deceased & 10 & 1.6 & Smoking & & \\
\hline Accommodation & & & Yes & 162 & 25.8 \\
\hline Living with their parents & 345 & 54.8 & No & 467 & 74.2 \\
\hline Away from parental home at & 284 & 45.2 & Cannabis consumption & & \\
\hline least a part of the time & & & Yes & 75 & 11.9 \\
\hline Part-time job & & & No & 554 & 88.1 \\
\hline Yes & 86 & 13.7 & Other drugs consumption & & \\
\hline No & 543 & 86.3 & Yes & 17 & 2.7 \\
\hline Number of main daily meals & & & No & 612 & 97.3 \\
\hline One meal & 12 & 1.9 & Alcohol consumption & & \\
\hline Two meals & 167 & 26.6 & Never & 226 & 35.9 \\
\hline Three meals & 446 & 70.9 & Occasional & 388 & 61.7 \\
\hline Four meals or more & 4 & 0.6 & Daily & 15 & 2.4 \\
\hline Number of snacks between meals & & & Self-reported oral health & & \\
\hline None & 142 & 22.6 & Good health & 580 & 92.2 \\
\hline One snack & 368 & 58.5 & Poor health & 49 & 7.8 \\
\hline Two snacks or more & 119 & 18.9 & Dental visit during the past year & & \\
\hline Daily consumption of sugar drinks & & & Yes & 369 & 58.7 \\
\hline None & 298 & 47.4 & No & 260 & 41.3 \\
\hline One drink & 251 & 39.9 & Reason for the last dental consultation & & \\
\hline Two drinks or more & 80 & 12.7 & Preventive & 431 & 68.5 \\
\hline Daily consumption of candies & & & Curative & 167 & 26.6 \\
\hline Yes & 74 & 11.8 & Not known & 31 & 4.9 \\
\hline No & 555 & 88.2 & Failing to seek dental care due to financial reasons & & \\
\hline Daily consumption of sugar-free chewing gums & & & Yes & 34 & 5.4 \\
\hline Yes & 133 & 21.1 & No & 595 & 94.6 \\
\hline
\end{tabular}

Table 1 Background factors, daily health-related behaviors and oral-health behaviors among the first-year students of Nice Côte d'Azur University (Continued) 
calculation provided a number of at least 377 subjects for an absolute error of $5 \%$ and a type I error of $5 \%$.

\section{Investigators calibration}

The investigators were ten final-year dental students who were previously trained to work in pairs. The questionnaire with closed questions was developed, and its use according to standardized modalities was validated for previous studies (Additional file 1) [23, 42, 43]. A very descriptive document was used to explain all of the recorded variables and the manner in which they should be coded. Sessions of tutorial classes were conducted by an experienced teacher to calibrate the operators to ensure that the interviews were led according to standardized modalities.

Our final-year dental students have a clinical experience of 2 years. Sessions of tutorial classes were also conducted to calibrate the operators. During these sessions, the inter- and intra-operator reliabilities (at a one-week interval) were assessed. Each operator was trained and became eligible for the study if all of the calculated Cohen kappa values (for qualitative variables) and intra-class correlation coefficients (for quantitative variables) exhibited minimum acceptable inter- and intra-operator agreement of more than 0.80 .

\section{Recruitment procedure}

Participation in the study was proposed to all first-year undergraduate students who attended the medical examination in the first half of 2015. All students were eligible for the study with no exclusion criteria. After information on the objectives of the study was provided and the student's consent was obtained, information was collected through an interview and an oral examination. The interview and oral examination were immediately conducted in the unit for medical examination in the university department of preventive medicine, which was adapted for this purpose.

\section{Collected data}

A closed room was equipped with a dentist chair to provide privacy for study participants. Appropriate dental lighting was a part of the unit. Disposable periodontal examination kits with a probe, mirror and cotton rolls were used, as were masks and disposable gloves. Data entry was anonymous, and no information in the electronic file could be used to identify the source person. The students were interviewed using standardized modalities and a questionnaire with closed questions about sociodemographic data that included the following: areas of study (Health and Sport, Science and Technology, Law and Economics, Management and Business, or Letters and Arts and Humanities), age, gender, social security coverage (French social security system, health mutual or supplementary universal health-care coverage, or other systems), father's and mother's professions (management profession, employees, or without employment), accommodation status (living with their parents or away from the parental home for at least part of the time), part-time jobs, dietrelated behaviors (number of main daily meals; number of snacks between meals; daily consumption of sugary drinks, candies, sugar-free chewing gums; the drink consumed when thirsty, i.e., water or other drinks), oral hygiene habits (daily toothbrushing frequency, i.e., one, two or three times or not every day), type of toothbrush used (electric or manual), frequency of toothbrush replacement (at least every 3 months), place of toothpaste purchase (pharmacy or supermarket), flossing, addictive behaviors (smoking, alcohol consumption, consumption of cannabis or other drugs), oral health-related behaviors (self-reported oral health, i.e., good or poor health; dental visits during the past year; reason for the last dental consultation, i.e., preventive or curative; and failure to seek dental care due to financial reasons).

The oral examination assessed dental crowding by measuring the most crowded arch (no crowding between 0 and $2 \mathrm{~mm}$, mild or moderate crowding between 2.1 and $7.0 \mathrm{~mm}$, and severe crowding more than $7 \mathrm{~mm}$ ) [44], periodontal status using the Community Periodontal Index of Treatment Needs (CPITN) (0: no signs of disease; 1: gingival bleeding after gentle probing; 2: presence of supra or subgingival calculus; 3 : shallow pockets of 4-5 $\mathrm{mm}$; and 4: pockets of $6 \mathrm{~mm}$ or more), oral hygiene using the Silness-Löe plaque index (0: no observable plaque; 1 : a thin film of plaque detected at the gingival margin by running a probe across the tooth surfaces; 2: a moderate amount of plaque detected along the gingival margin with plaque visible clinically; and 3: heavy plaque accumulation detected at the gingival margin and in the interdental spaces), the calculus index (0: no observable calculus; 1 : scattered calculus covering less than one-third of the buccal surface of the tooth; 2 : calculus covering between one- and two-thirds of the buccal tooth surface with minimal subgingival calculus; and 3: calculus covering greater than two-thirds of the buccal tooth surface and extending subgingivally), the presence or absence of pit and fissure sealant remnants, the presence or absence of restorative care, and the DMFT index (decayed, missing, or filled teeth; only cavitated carious lesions were considered in this screening situation).

\section{Statistical analysis}

The risk factors were initially subjected to univariate analyses. The dependent variable was dichotomous (i.e., the presence or absence of at least one carious lesion at the time of the oral examination). The independent 
variables with more than two categories were dichotomized as follows for the statistical analyses: Health/Sport area of study vs others, father's profession in management vs others, mother's profession in management vs others, at least 3 main meals per day vs less than 3 main meals per day, at most one snack per day vs more than one snack per day, no daily soft drink consumption vs daily consumption, toothbrushing at least twice per day vs less than twice per day, daily alcohol consumption vs no daily consumption, and preventive reason for the last dental consultation vs curative or unknown reason. To determine which variables were significantly related to our variable of interest, each variable was examined separately from the others, and the chi-square test (or Fisher's exact test) was applied. The $p$ value was set at 0.05 .

A multivariate logistic regression analysis was used to identify the risk factors that predicted the development of carious lesions. Any independent variable that yielded a significant univariate test result at the level of 0.25 was selected as a candidate for the multivariate analysis. The major purpose of this technique was to quantify the strengths of the associations between the dependent variable and each of the independent variables (odds ratios) by accounting for the effects of the other modelintegrated variables. The main advantage of this approach is the avoidance of confounding effects caused by analyzing the associations of all variables together. The forward stepwise likelihood ratio method for analyses was used.

\section{Results}

Six hundred twenty-nine students in their first year of study were enrolled in this study (Table 1). The average age was $18.8 \pm 1.6$ years. The sex ratio was 0.72 , with a strong predominance of the female gender. The DMFT was $1.20 \pm 2.07(\mathrm{D}=0.43 \pm 1.20 ; \mathrm{M}=0.02 \pm 0.13$; and $\mathrm{F}$ $=0.75 \pm 1.63$ ). Only $59.3 \%$ of the students had never experienced dental caries, while $22.4 \%$ had already undergone restorative procedures and did not have any carious lesions at the time of the examination, and $11.6 \%$ presented carious lesions and had never been treated by a dentist (Table 2). Lastly, 6.7\% had carious lesions despite evidence of prior restorative procedures.

\section{Results of the univariate analyses and selection of the explanatory variables}

The main variables associated with the presence of at least one carious lesion were the professional status of the mother, i.e., whether she had an intermediate professional position as opposed to being unemployed or having a higher professional position $(p=0.028)$; the use of an electric toothbrush $(p=0.010)$; the presence of sealant remnants $(p=0.030)$; a preventive visit to the dentist $(p=0.001)$; smoking $(p=0.033)$; drinking something
Table 2 Oral examinations among first-year students of Nice Côte d'Azur University

\begin{tabular}{lll}
\hline & $\mathrm{N}$ & $\%$ \\
\hline Dental crowding & 501 & 79.7 \\
No crowding & 102 & 16.2 \\
Mild or moderate crowding & 26 & 4.1 \\
Severe crowding & & \\
Periodontal status & 482 & 76.6 \\
No signs of disease & 66 & 10.5 \\
Gingival bleeding & 80 & 12.7 \\
Supra- or subgingival calculus & 1 & 0.2 \\
Shallow pockets & & 80.6 \\
Poor oral hygiene (plaque and/or calculus) & 507 & 19.4 \\
No & 122 & \\
Yes & & 81.7 \\
Presence of at least one carious lesion & 514 & 18.3 \\
No & 115 & \\
Yes & & 70.9 \\
Presence of restorative care & 446 & 29.1 \\
No & 183 & \\
Yes & & \\
Pit and fissure sealant remnants & 591 & \\
Yes & 38 & \\
\hline
\end{tabular}

other than water when thirsty during the day $(\mathrm{p}=0.028)$; periodontal disease, even mild cases, revealed during the oral examination $(p=0.020)$; poor oral hygiene revealed by presence of dental plaque and/or calculus $(p<0.001)$; self-reported poor oral health $(\mathrm{p}<0.001)$; and failing to seek care due to financial reasons $(\mathrm{p}<0.001)$ (Table 3$)$.

\section{Ranking of the risk factors}

A regression analyses model was designed with the possible explanatory factors from the socioeconomic data (father's profession, mother's profession, and part-time job), dietary habits (at least 3 main meals per day, no daily soft drink consumption, water consumption when thirsty, daily candy consumption, and daily sugar-free chewing gum consumption), oral hygiene habits (use of an electric toothbrush and flossing), addictive behaviors (daily smoking and drug consumption), oral healthrelated behaviors (reason for last dental consultation, self-reported oral health, and failure to seek dental care due to financial reasons) and clinical data (presence of dental crowding, periodontal disease (even mild), sealant remnants, presence of restorative care, and poor oral hygiene revealed by presence of dental plaque and/or calculus). 
Table 3 Selection of the explanatory variables for inclusion in the logistic regression model $(p<0.25)$

\begin{tabular}{|c|c|c|c|c|}
\hline & & \multicolumn{2}{|c|}{$\begin{array}{l}\text { At least one } \\
\text { active carious } \\
\text { lesion ( } n)\end{array}$} & \multirow{2}{*}{$\begin{array}{l}\text { Univariate } \\
\text { Analysis } \\
\text { P }\end{array}$} \\
\hline & & NO & YES & \\
\hline \multirow[t]{2}{*}{ Gender } & Female & 297 & 69 & 0.677 \\
\hline & Male & 217 & 46 & \\
\hline \multirow[t]{2}{*}{ Area of study } & Health, Sport & 222 & 53 & 0.604 \\
\hline & Others & 292 & 62 & \\
\hline \multirow[t]{2}{*}{ Father's profession } & $\begin{array}{l}\text { Managing } \\
\text { profession }\end{array}$ & 264 & 49 & 0.099 \\
\hline & Others & 250 & 66 & \\
\hline \multirow[t]{2}{*}{ Mother's profession } & $\begin{array}{l}\text { Managing } \\
\text { profession }\end{array}$ & 175 & 27 & $0.028^{a}$ \\
\hline & Others & 339 & 88 & \\
\hline \multirow[t]{2}{*}{ Accommodation } & $\begin{array}{l}\text { Living with } \\
\text { their parents }\end{array}$ & 285 & 60 & 0.536 \\
\hline & Others & 229 & 55 & \\
\hline \multirow[t]{2}{*}{ Part-time job } & Yes & 64 & 22 & 0.071 \\
\hline & No & 450 & 93 & \\
\hline \multirow{2}{*}{$\begin{array}{l}\text { At least } 3 \text { main meals } \\
\text { per day }\end{array}$} & Yes & 375 & 75 & 0.109 \\
\hline & No & 139 & 40 & \\
\hline \multirow{2}{*}{$\begin{array}{l}\text { At the most one snack } \\
\text { per day }\end{array}$} & Yes & 414 & 96 & 0.513 \\
\hline & No & 100 & 19 & \\
\hline \multirow{2}{*}{$\begin{array}{l}\text { No daily soft drink } \\
\text { consumption }\end{array}$} & Yes & 253 & 45 & 0.063 \\
\hline & No & 261 & 70 & \\
\hline \multirow{2}{*}{$\begin{array}{l}\text { Water consumption } \\
\text { when thirsty }\end{array}$} & Yes & 404 & 79 & $0.028^{a}$ \\
\hline & No & 110 & 36 & \\
\hline \multirow[t]{2}{*}{ Daily candy consumption } & Yes & 55 & 19 & 0.108 \\
\hline & No & 459 & 96 & \\
\hline \multirow{2}{*}{$\begin{array}{l}\text { Daily sugar-free chewing } \\
\text { gum consumption }\end{array}$} & Yes & 102 & 31 & 0.101 \\
\hline & No & 412 & 84 & \\
\hline \multirow{2}{*}{$\begin{array}{l}\text { Toothbrushing at least twice } \\
\text { per day }\end{array}$} & Yes & 447 & 100 & 1.000 \\
\hline & No & 67 & 15 & \\
\hline \multirow[t]{2}{*}{ Use of electric toothbrush } & Yes & 90 & 9 & $0.010^{\mathrm{a}}$ \\
\hline & No & 424 & 106 & \\
\hline \multirow[t]{2}{*}{ Flossing } & Yes & 68 & 8 & 0.080 \\
\hline & No & 446 & 107 & \\
\hline \multirow{2}{*}{$\begin{array}{l}\text { Toothbrush replacement at } \\
\text { least every } 3 \text { months }\end{array}$} & Yes & 380 & 80 & 0.353 \\
\hline & No & 134 & 35 & \\
\hline \multirow{2}{*}{$\begin{array}{l}\text { Purchase of toothpaste at } \\
\text { the pharmacy }\end{array}$} & Yes & 49 & 9 & 0.721 \\
\hline & No & 465 & 106 & \\
\hline \multirow[t]{2}{*}{ Daily smoking } & Yes & 123 & 39 & $0.033^{a}$ \\
\hline & No & 391 & 76 & \\
\hline \multirow[t]{2}{*}{ Cannabis consumption } & Yes & 60 & 15 & 0.637 \\
\hline & No & 454 & 100 & \\
\hline Another drugs consumption & Yes & 12 & 5 & 0.214 \\
\hline
\end{tabular}

Table 3 Selection of the explanatory variables for inclusion in the logistic regression model $(p<0.25)$ (Continued)

\begin{tabular}{|c|c|c|c|c|}
\hline & & \multicolumn{2}{|c|}{$\begin{array}{l}\text { At least one } \\
\text { active carious } \\
\text { lesion ( } n \text { ) }\end{array}$} & \multirow{2}{*}{$\begin{array}{l}\text { Univariate } \\
\text { Analysis } \\
\text { P }\end{array}$} \\
\hline & & NO & YES & \\
\hline & No & 502 & 110 & \\
\hline \multirow[t]{2}{*}{ Daily alcohol consumption } & Yes & 12 & 3 & 0.740 \\
\hline & No & 502 & 112 & \\
\hline \multirow[t]{2}{*}{ Presence of dental crowding } & Yes & 99 & 29 & 0.160 \\
\hline & No & 415 & 86 & \\
\hline \multirow[t]{2}{*}{ Periodontal disease, even mild } & Yes & 110 & 37 & $0.020^{\mathrm{a}}$ \\
\hline & No & 404 & 78 & \\
\hline \multirow[t]{2}{*}{ Sealant remnants } & Yes & 36 & 2 & $0.030^{a}$ \\
\hline & No & 478 & 113 & \\
\hline \multirow[t]{2}{*}{ Presence of restorative care } & Yes & 141 & 42 & 0.055 \\
\hline & No & 373 & 73 & \\
\hline \multirow{2}{*}{$\begin{array}{l}\text { Poor oral hygiene (plaque } \\
\text { and/or calculus) }\end{array}$} & Yes & 82 & 40 & $<0.001^{a}$ \\
\hline & No & 432 & 75 & \\
\hline \multirow{2}{*}{$\begin{array}{l}\text { Dental visit during the } \\
\text { past year }\end{array}$} & Yes & 305 & 64 & 0.466 \\
\hline & No & 209 & 51 & \\
\hline \multirow{2}{*}{$\begin{array}{l}\text { Reason for last dental } \\
\text { consultation }\end{array}$} & Preventive & 367 & 64 & $0.001^{a}$ \\
\hline & Other reason & 147 & 51 & \\
\hline \multirow[t]{2}{*}{ Self-reported oral health } & Good & 486 & 94 & $<0.001^{a}$ \\
\hline & Bad & 28 & 21 & \\
\hline \multirow{2}{*}{$\begin{array}{l}\text { Failing to seek dental care } \\
\text { due to financial reasons }\end{array}$} & Yes & 19 & 15 & $<0.001^{a}$ \\
\hline & No & 495 & 100 & \\
\hline
\end{tabular}

${ }^{\mathrm{a} S i g n i f i c a n t}$

The multivariate analysis identified pejorative risk factors and ranked them as follows: failure to seek dental care due to financial reasons (OR:3.06, 95\% CI: 1.406.70 ), poor oral hygiene revealed during the oral examination (OR: 2.59, 95\% CI: 1.60-4.20), and poor selfreported oral health (OR: 2.43, 95\% CI: 1.24-4.77) (Table 4). Conversely, this study also highlighted and ranked the protective factors as follows: a preventive visit to the dentist (OR: $0.63,95 \%$ CI: $0.41-0.99$ ), the use of an electric toothbrush (OR: 0.36, 95\% CI: 0.17-0.77), and the presence of pit and fissure sealant remnants (OR: 0.22, 95\% CI: 0.05-0.97).

\section{Discussion}

The multivariate analysis made it possible to rank the risk factors for dental caries among the first-year university students of Nice in the first half of 2015. These risk factors were failure to seek dental care due to financial reasons followed by poor oral hygiene revealed during the oral examination and poor self-reported oral health.

In 2014, the Student Life Observatory published the results of a national survey about the living conditions 
Table 4 Results from the logistic regression analyses with the dependent variable "presence of at least one carious lesion"

\begin{tabular}{|c|c|c|c|c|}
\hline \multirow[t]{2}{*}{ Variables in the final equation } & \multirow[t]{2}{*}{ Sig. } & \multirow{2}{*}{$\begin{array}{l}\text { Odds } \\
\text { Ratio }\end{array}$} & \multicolumn{2}{|l|}{$95 \% \mathrm{Cl}$} \\
\hline & & & Lower & Upper \\
\hline Use of an electric toothbrush & 0.008 & 0.360 & 0.169 & 0.766 \\
\hline Last dental consultation for a preventive reason & 0.045 & 0.634 & 0.406 & 0.990 \\
\hline Presence of sealant remnants & 0.045 & 0.223 & 0.052 & 0.969 \\
\hline Poor oral hygiene & 0.000 & 2.585 & 1.590 & 4.202 \\
\hline Failing to seek dental care due to financial reasons & 0.005 & 3.060 & 1.397 & 6.700 \\
\hline Poor self-reported oral health & 0.010 & 2.428 & 1.236 & 4.767 \\
\hline
\end{tabular}

of students in France [45]. Among other findings, this survey revealed that $11 \%$ of the students were not satisfied with their current health status and that $13 \%$ confessed to having already failed to seek medical care due to financial reasons. Many social assistance programs exist, for example, universal supplementary health coverage (CMUc [couverture maladie complémentaire universelle]) (free supplementary health coverage meant to facilitate access to healthcare for the low-income population with a stable and regular residence in France) and payment assistance for the supplementary health aid system (ACS [aide au paiement d'une complémentaire santé]) (aid that offers discounts on the premiums for supplementary health coverage for low-income populations with incomes slightly higher than the limit set for the allocation of $\mathrm{CMUc}$ ). These programs make it possible to provide 100\% dental coverage in France [46]. In 2015 , a French national report revealed that $19.1 \%$ of students lived below the poverty line, i.e., less than 987 euros per month. The advance of dental fees can be perceived as unaffordable in this context [47].

The presence of dental plaque and/or calculus revealed during the oral examination can likely be more strongly attributed to the inadequate behavior of some students. Nevertheless, the French Union for Oral Health (UFSBD [Union Française pour la Santé Bucco-Dentaire]) issues good practice guidelines for the general public to ensure adequate oral hygiene. More specifically, this organization focuses on adults under the age of 40 and recommends at least two brushings per day, the use of fluoride toothpastes, the use of floss in the evening, a preventive visit to the dentist at least once per year, and the use of sugarfree chewing gums after each food intake [48].

The univariate analysis also highlighted the possible role of periodontal disease, even mild cases. Yet, gingivitis is often correlated with the presence of plaque, which is the consequence of a lack of brushing. Both periodontal status and poor oral hygiene were included in the multivariate logistic regression model, and only poor oral hygiene remained a proven risk factor. The main advantage of the multivariate analysis was thus to avoid confounding effects that arise by analyzing the associations of all variables together. Good practice guidelines are not sufficient to enhance a good oral hygiene for students. Actually, in France, there is no dental hygienist to educate patients in regard to diet and oral hygiene habits. Nevertheless, the success of the dental hygienist in the dental health education of patients has long been recognized in terms of influencing behavior [49]. A Swedish study revealed that patients' attitudes were less negative towards dental hygienists than towards dentists [50]. This difference was more pronounced among students than general patients and patients with periodontal disease. Therefore, this specific population could greatly benefit from the introduction of dental hygienists in France.

The highest-ranking caries protective factor among the study population was the use of dental sealants, followed by the use of an electric toothbrush and a preventive visit to the dentist. Sealants are used and have been recommended in France since the early 2000s, and their efficacy is well documented [51]. The role played by the presence of sealant remnants is thus not surprising. Our results also confirmed recent studies that tend to prove the superiority of the use of electric brushing over manual brushing [52]. Preventive dental consultations remain rare in France despite institutional incentives. Since 2007 the "M'T dents" (love your teeth!) program has been offering all children aged 6, 9, 12, 15 and 18 one free dental consultation and treatment, if necessary [53]. The purpose of this initiative was to develop the habit of preventively visiting the dentist. However, $41 \%$ of the students had not visited the dentist in the previous year. Moreover, the reason for the last dental appointment was preventive in only $69 \%$ of the cases.

The strengths of our study lie in supplying French data on a rarely studied population. The originality comes from the peer-led action among students. A study conducted in India focused primarily on dental students and 
revealed the positive attitude of this category of students towards their own oral health [54]. The authors mentioned the potential interest of a peer-driven prevention approach (dental students versus the students of other fields) to promote oral health on university campuses.

The limitations of our study arise from both the participation of only volunteer students and the crosssectional design, which only provides a snapshot of our outcome at a specific point in time and provides no indication of the sequence of events. The oral examinations were performed in screening conditions, and an underestimation of the number of students affected by caries is possible. However, the use of recognized indices to estimate the dental caries status (i.e., the DMFT index), the oral hygiene (i.e., the plaque index and the calculus index) and the periodontal status (i.e., CPITN) likely limit these biases.

\section{Conclusions}

Students are known to neglect their oral hygiene and are particularly vulnerable to dental decay. The highestranking caries risk factor for the study population was the financial barrier.

\section{Additional file}

Additional file 1: questionnaire used for the interview of the students. The questionnaire consisted in five parts including socio-economic information, daily diet-related behaviors, addictive behaviors, oral hygiene habits and oral health-related behaviors. (DOCX $17 \mathrm{~kb}$ )

\section{Abbreviations}

Cl: Confidence interval; CPITN: Community periodontal index of treatment needs; DMFT: Decayed, missing or filled teeth; mm: millimeters; OR: Odd ratio; Sig.: Significance

\section{Acknowledgements}

Not applicable

\section{Funding}

This study received no specific grant from any public, commercial, or not-forprofit funding agency.

\section{Availability of data and materials}

The datasets used and/or analysed during the current study are available from the corresponding author on reasonable request.

\section{Authors' contributions \\ RC participated in the collection, analysis and interpretation of data, drafted the manuscript and contributed to revising critically the manuscript. MFB contributed to conception and design of the study, analysis and interpretation of data, helped to draft the manuscript and contributed to revising critically the manuscript. CC participated in the collection and interpretation of data, and contributed to revising critically the manuscript. LL conceived of the study, established the experimental design, performed the statistical analysis, participated in the analysis and interpretation of data, helped to draft the manuscript, and contributed to revising critically the manuscript. All authors read and approved the final version of the manuscript.}

\section{Authors' information}

RC: DDS, Associate Professor, Department of Conservative Dentistry and Endodontics, Université Côte d'Azur.
MFB: DDS, PhD, Professor, Head of the Department of Conservative Dentistry and Endodontics,

Université Côte d'Azur.

CC: DDS, Instructor, Department of Dental Public Health, Université Côte d'Azur.

LL: DDS, PhD, Professor, Head of the Department of Dental Public Health, Université Côte d'Azur.

\section{Ethics approval and consent to participate}

The study was approved by the University institutional review board ([Commission de la Formation et de la Vie Universitaire]). The data were obtained from preventive medical consultations made in routine. Moreover, students were invited to voluntarily attend the dental exam. After information on the objectives of the study and verbal student's consent, information was collected through an oral interview and an electronic input of the data. Data entry was anonymous and the gathered information in the electronic file does not permit to identify the source person.

\section{Consent for publication}

Not applicable

\section{Competing interests}

The authors declare that they have no competing interests.

\section{Publisher's Note}

Springer Nature remains neutral with regard to jurisdictional claims in published maps and institutional affiliations.

\section{Author details}

'Université Côte d'Azur, UFR Odontologie, 24 avenue des diables bleus, 06357 Nice cedex 4, France. ${ }^{2}$ Université Aix-Marseille, ADES, bd Pierre Dramard, 13334, Marseille cedex 15, France. ${ }^{3}$ Université Côte d'Azur, MICORALIS, 24 avenue des diables bleus, 06357 Nice cedex 4, France. ${ }^{4}$ Centre Hospitalier Universitaire de Nice, Pôle d'Odontologie, 5 Rue Dévoluy, 06000 Nice, France. ${ }^{5}$ UFR Odontologie, Pôle Universitaire Saint Jean d'Angély, 24 avenue des diables bleus, 06357 Nice cedex 4, France.

Received: 28 March 2017 Accepted: 10 December 2017

Published online: 21 December 2017

\section{References}

1. Commission des affaires culturelles, familiales et sociales. Rapport d'information en conclusion des travaux d'une mission d'information sur la santé et la protection sociale des étudiants n³494. 2006. http://www. assemblee-nationale.fr/12/rap-info/i3494.asp. Accessed 1 Aug 2016.

2. Selwitz RH, Ismail Al, Pitts NB. Dental caries. Lancet. 2007:369:51-9.

3. Hicks MJ, Flaitz CM. Epidemiology of dental caries in the pediatric and adolescent population: a review of past and current trends. J Clin Pediatr Dent. 1993;18:43-9.

4. Sakki TK, Knuuttila ML, Anttila SS. Lifestyle, gender and occupational status as determinants of dental health behavior. J Clin Periodontol. 1998;25:566-70.

5. Anderson M. Risk assessment and epidemiology of dental caries: review of the literature. Pediatr Dent. 2002;24:377-85.

6. Featherstone JD, Adair SM, Anderson MH, Berkowitz RJ, Bird WF, Crall JJ, et al. Caries management by risk assessment: consensus statement, Apri 2002. J Calif Dent Assoc. 2003;31:257-69.

7. Bellini HT, Arneberg P, von der Fehr FR. Oral hygiene and caries. A review Acta Odontol Scand. 1981;39:257-65.

8. Mascarenhas AK. Oral hygiene as a risk indicator of enamel and dentin caries. Community Dent Oral Epidemiol. 1998;26:331-9.

9. Etty EJ, Henneberke M, Gruythuysen RJ, Wöltgens JH. Influence of oral hygiene on early enamel caries. Caries Res. 1994;28:132-6.

10. Marshall TA, Levy SM, Broffitt B, Warren JJ, Eichenberger-Gilmore JM, Burns $\mathrm{TL}$, et al. Dental caries and beverage consumption in young children. Pediatrics. 2003;112:e184-91.

11. Shenkin JD, Heller KE, Warren JJ, Marshall TA. Soft drink consumption and caries risk in children and adolescents. Gen Dent. 2003;51:30-6.

12. Moynihan P, Petersen PE. Diet, nutrition and the prevention of dental diseases. Public Health Nutr. 2004;7:201-26. 
13. Sheiham A, James WP. A new understanding of the relationship between sugars, dental caries and fluoride use: implications for limits on sugars consumption. Public Health Nutr. 2014;17:2176-84.

14. Deery C. Strong evidence for the effectiveness of resin based sealants. Evid Based Dent. 2013;14:69-70.

15. Ahovuo-Saloranta A, Forss H, Walsh T, Hiiri A, Nordblad A, Mäkelä M, et al. Sealants for preventing dental decay in the permanent teeth. Cochrane Database Syst Rev. 2013;3:CD001830.

16. Hafez HS, Shaarawy SM, Al-Sakiti AA, Mostafa YA. Dental crowding as a caries risk factor: a systematic review. Am J Orthod Dentofac Orthop. 2012; 142:443-50.

17. Walsh T, Worthington HV, Glenny AM, Appelbe P, Marinho VC, Shi X. Fluoride toothpastes of different concentrations for preventing dental caries in children and adolescents. Cochrane Database Syst Rev. 2010;1:CD007868.

18. Kirchhoff J, Filippi A. Comparison of oral health behavior among dental students, students of other disciplines, and fashion models in Switzerland. Swiss Dent J. 2015:125:1337-44.

19. Halboub E, Dhaifullah E, Yasin R. Determinants of dental health status and dental health behavior among Sana'a university students, Yemen. J Investig Clin Dent. 2013;4:257-64

20. Garcia-Cortes JO, Medina-Solis CE, Loyola-Rodriguez JP, Mejia-Cruz JA, Medina-Cerda E, Patino-Marin N, et al. Dental caries' experience, prevalence and severity in Mexican adolescents and young adults. Rev Salud Publica. 2009;11:82-91.

21. Peltola JS, Ventä I, Haahtela S, Lakoma A, Ylipaavalniemi P, Turtola L. Dental and oral radiographic findings in first-year university students in 1982 and 2002 in Helsinki. Finland Acta Odontol Scand. 2006;64:42-6.

22. Yamane-Takeuchi M, Ekuni D, Mizutani S, Kataoka K, Taniguchi-Tabata A, Azuma T, et al. Associations among oral health-related quality of life, subjective symptoms, clinical status, and self-rated oral health in Japanese university students: a cross-sectional study. BMC Oral Health. 2016;16:127.

23. Ceinos R, Cucchi C, Bertrand MF, Lupi-Pegurier L. Caries experience and treatment needs among the students of nice - Sophia Antipolis university. Caries Res. 2014;48:398

24. Kunitomo M, Ekuni D, Mizutani S, Tomofuji T, Irie K, Azuma T, et al. Association between knowledge about comprehensive food education and increase in dental caries in Japanese university students: a prospective cohort study. Nutrients. 2016:8:114.

25. Kassak KM, Dagher R, Doughan B. Oral hygiene and lifestyle correlates among new undergraduate university students in Lebanon. J Am Coll Heal. 2001;50:15-20.

26. Kirtilogu T, Yavuz US. An assessment of oral self-care in the student population of a Turkish university. Public Health. 2006;120:953-7.

27. Luebke TE, Driskell JA. A group of Midwestern university students needs to improve their oral hygiene and sugar/pop consumption habits. Nutr Res. 2010;30:27-31

28. Kojima A, Ekuni D, Mizutani S, Furuta M, Irie K, Azuma T, et al. Relationships between self-rated oral health, subjective symptoms, oral health behavior and clinical conditions in Japanese university students: a cross-sectional survey at Okayama University. BMC Oral Health. 2013;13:62.

29. Rimondini L, Zolfanelli B, Bernardi F, Bez C. Self-preventive oral behavior in an Italian university student population. J Clin Periodontol. 2001;28:207-11.

30. Walker AR, Cleaton-Jones PE. Sugar intake and dental caries. Br Dent J. 1992;172:7.

31. Axelsson P, Paulander J, Lindhe J. Relationship between smoking and dental status in 35-, 50-, 65-, and 75-year-old individuals. J Clin Periodontol. 1998;25:297-305.

32. Holmen A, Stromberg U, Magnusson K, Twetman S. Tobacco use and caries risk among adolescents - a longitudinal study in Sweden. BMC Oral Health. 2013;13:31.

33. Harris C, Warnakulasuriya KA, Gelbier S, Johnson NW, Peters TJ. Oral and dental health in alcohol misusing patient. Alcohol Clin Exp Res. 1997;21:1707-9.

34. Dasanayake AP, Warnakulasuriya S, Harris CK, Cooper DJ, Peters TJ. Tooth decay in alcohol abusers compared to alcohol and drug abusers. Int J Dent. 2010;ID786503:1-6.

35. Priyanka K, Sudhir KM, Reddy VCS, Kumar RK, Srinivasulu G. Impact of alcohol dependency on oral health - a cross-sectional comparative study. J Clin Diagn Res. 2017;11:ZC43-6.

36. Angelillo IF, Grasso GM, Sagliocco G, Villari P, D’Errico MM. Dental health in a group of drug addicts in Italy. Community Dent Oral Epidemiol. 1991;19:36-7.

37. Shetty V, Mooney LJ, Zigler CM, Belin TR, Murphy D, Rawson R. The relationship between methamphetamine use and increased dental disease. J Am Dent Assoc. 2010;141:307-18.
38. Cury PR, Oliveira MG, de Andrade KM, de Freitas MD, Dos Santos JN. Dental health status in crack/cocaine-addicted men: a cross-sectional study. Environ Sci Pollut Res Int. 2017;24:7585-90.

39. Ministère de l'Education Nationale, de l'Enseignement Supérieur, de la Recherche. Repères et Références Statistiques 2015 sur les enseignements, la formation et la recherche. http://www.enseignementsup-recherche.gouv. fr/cid92179/reperes-et-references-statistiques-edition-aout-2015.html. Accessed 1 Aug 2017.

40. Pohjola V, Rekola A, Kunttu K, Virtanen Jl. Association between dental fear and oral health habits and treatment need among university students in Finland: a national study. BMC Oral Health. 2016;16:26.

41. Journal Officiel de la République Française. Decree no. 2008-1026 of October 7th, 2008 concerning the organization and the missions of the university and interuniversity services of preventive and health-promoting medicine. 2008. https://www.legifrance.gouv.fr/affichTexte.do?cidTexte= JORFTEXT000019591463. Accessed 1 Aug 2016.

42. Lupi-Pegurier L, Sionneau R, Bertrand MF, Moretti J, Bolla M, Muller-Bolla M. Oral health promotion through peer support among students in nice. J Dent Res. 2010;89:abstract 4638.

43. Bertrand MF, Sionneau R, Muller-Bolla M, Bolla M, Lupi-Pegurier L. Three years of peer-led oral health promotion among students. J Dent Res. 2012; 91:abstract 776

44. Gelgör IE, Karaman Al, Ercan E. Prevalence of malocclusion among adolescents in central Anatolia. Eur J Dent. 2007;1:125-31.

45. Observatoire National de la Vie Etudiante. National survey of living conditions 2013: the health of students. 2014. http://www.ove-national.education.fr/ medias/OVEDonnees_sante_CDV2013.pdf. Accessed 1 Aug 2016.

46. Assurance Maladie. CMUc universal supplementary health coverage. 2016. https://www.cmu.fr/cmu-complementaire.php. Accessed 1 Aug 2016.

47. Inspection Générale des Affaires Sociales. Evaluation de la Zème année de mise en œuvre du plan pluriannuel contre la pauvreté et pour l'inclusion sociale. Rapport N²014-049R. www.igas.gouv.fr/IMG/pdf/Rapport_2014049R_TOME_I.pdf. Accessed 5 Sept 2017.

48. Union Française pour la Santé Bucco-Dentaire. Recommendations of oral hygiene, adults of less than 40 years. 2016. http://www.ufsbd.fr/espacegrand-public/votre-sante-bucco-dentaire/adultes-de-moins-de-40-ans/. Accessed 1 Aug 2016

49. Uitenbroek DG, Schaub RM, Tromp JA, Kant JH. Dental hygienists' influence on the patients' knowledge, motivation, self-care, and perception of change. Community Dent Oral Epidemiol. 1989;17:87-90.

50. Ohrn K, Hakeberg M, Abrahamsson KH. Dental beliefs, patients' specific attitudes towards dentists and dental hygienists: a comparative study. Int J Dent Hyg. 2008;6:205-13.

51. Wright JT, Tampi MP, Graham L, Estrich C, Crall JJ, Fontana M, et al. Sealants for preventing and arresting pit-and-fissure occlusal caries in primary and permanent molars: a systematic review of randomized controlled trials-a report of the American dental association and the American Academy of pediatric dentistry. J Am Dent Assoc. 2016;147:631-45.

52. Yaacob M, Worthington HV, Deacon SA, Deery C, Walmsley A, Robinson PG, et al. Powered versus manual toothbrushing for oral health. Cochrane Database Syst Rev. 2014;6:CD002281.

53. Assurance Maladie. The oral examination M'T dents. 2015. http://www.ameli. fr/assures/prevention-sante/les-examens-bucco-dentaires/l-examen-buccodentaire-m-t-dents.php. Accessed 1 Aug 2016.

54. Mani PM, Swamy RM, Manjunath GN, Venkatesk G, Venkateshappa C, Kumar N. Attitude of dental students towards their oral health care. Res J Pharm Biol Chem Sci. 2013:4:755-9. 